\title{
Growth and Characterization of Benzimidazolium Salicylate: NLO Property from a Centrosymmetric Crystal
}

\author{
M. Amudha, ${ }^{1,2}$ R. Rajkumar, ${ }^{1}$ V. Thayanithi, ${ }^{1}$ and P. Praveen Kumar ${ }^{1}$ \\ ${ }^{1}$ Department of Physics, Presidency College, Chennai, Tamil Nadu 600005, India \\ ${ }^{2}$ Department of Physics, Aalim Muhammed Salegh College of Engineering, Avadi, Chennai, Tamil Nadu 600055, India \\ Correspondence should be addressed to P. Praveen Kumar; ppkpresidency@gmail.com
}

Received 15 July 2015; Revised 16 September 2015; Accepted 16 September 2015

Academic Editor: Giancarlo C. Righini

Copyright (c) 2015 M. Amudha et al. This is an open access article distributed under the Creative Commons Attribution License, which permits unrestricted use, distribution, and reproduction in any medium, provided the original work is properly cited.

\begin{abstract}
A new organic charge transfer molecular complex salt of benzimidazolium salicylate (BSL) single crystals was grown by the slow evaporation solution growth technique using methanol as a solvent at room temperature. The grown crystals were characterised by single crystal X-ray diffraction (XRD) which confirms that the crystal belongs to monoclinic system with the centrosymmetric space group $\mathrm{P} 2 / c$. The crystalline perfection of the grown crystal was analyzed by high resolution X-ray diffraction (HRXRD). The presence of various functional groups was identified by FTIR spectrum. UV-Vis spectral study reveals that the BSL crystal is optically transparent in the wavelength region $342 \mathrm{~nm}-1100 \mathrm{~nm}$. Dielectric measurements of the crystal at various frequencies were also determined. The mechanical properties of the grown crystal were assessed using Vickers microhardness testing. Nonlinear optical property of the crystal was confirmed using Kurtz and Perry powder technique and the SHG efficiency of the BSL crystal is 0.7 times greater than that of the standard KDP crystal.
\end{abstract}

\section{Introduction}

In recent years, organic materials have attracted many researchers due to its high nonlinearities, ultrafast response in electrooptic effect, large optical susceptibilities, large second order molecular polarizability, and higher resistance to optical damage and they have wide applications in optical communications, frequency mixing, optical parametric oscillation, information storage, and so forth [1-4]. According to crystal engineering, second harmonic generation occurs mostly in noncentrosymmetric crystals due to nonzero hyperpolarizability. But some of the recent reports of organic molecular complexes like caffenium picrate [5], picolinium maleate [6], guanidinium trifluoroacetate, and so forth have highlighted that even centrosymmetric crystals possess SHG effect due to the presence of delocalized $\pi$ electron system linking donor and acceptor groups which enhance the necessary asymmetric polarizability [7, 8]. The various organic subnetworks enhance the thermal and mechanical stabilities through hydrogen bonding interactions and behave as noncentrosymmetry material in the bulk $[9,10]$. In organic molecular charge transfer complexes, the charge transfer interaction and molecular aggregation through intermolecular hydrogen bonding has been entrenched by single crystal XRD analysis [11, 12].

Benzimidazole is a very good proton acceptor and, in the presence of a carboxylic acid, it will always deprotonate that group. Hence it is widely used in the formation of organic molecular complex salts like benzimidazolium hydrogen phenylmalonate, benzimidazolium hydrogen nitroterepthalate, 2 methyl benzimidazolium picrate, and so forth [1315]. According to Mulliken, the charge transfer interactions between two aromatic molecules arise due to the transfer of an electron from Lewis base to Lewis acid and have attracted considerable attention on these complexes for their nonlinear optical properties [16, 17]. The researchers have reported recently Benzimidazole based organic compounds with good nonlinear properties such as $1 \mathrm{H}$ benzimidazolium hydrogen L-tartrate dihydrate [18], benzil doped Benzimidazole [19], benzimidazolium per chlorate [20]. Similarly salicylic acid forms salicylate salts with various organic molecules and forms salts through hydrogen bonding interactions like Urea salicylate, Bis Guanidinium 5 sulfosalicylate, and Brucinium 5 sulfosalicylate trihydrate and they are reported as efficient 


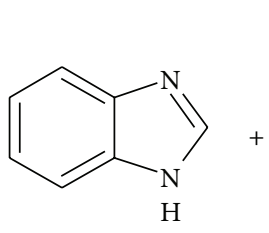

Benzimidazole

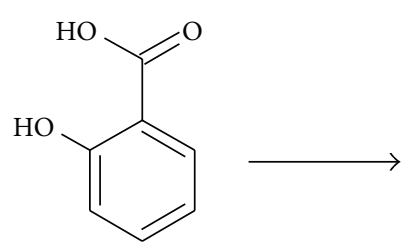

Salicylic acid<smiles>O=C([O-])c1ccccc1O</smiles>

Benzimidazolium salicylate

FIGURE 1: Reaction scheme for BSL.

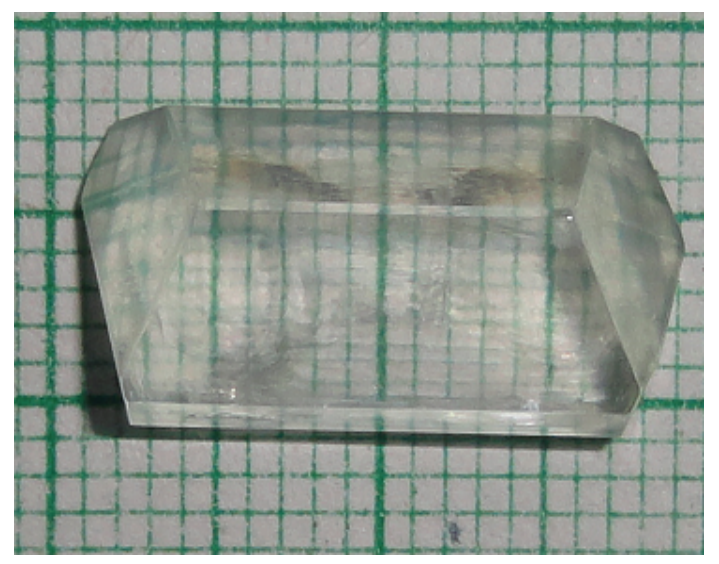

FIGURE 2: As grown BSL crystal of dimension $19 \times 9 \times 4 \mathrm{~mm}^{3}$.

NLO materials [21-23]. The formation of hydrogen bonding in benzimidazolium organic complex salts was reported. In the present work, the Benzimidazole molecule is protonated through hydrogen transfer from the carboxylic group on the 2-hydroxy benzoic acid (salicylic acid). In this paper the synthesis, crystal growth, and structural, spectral, optical, and mechanical properties of the benzimidazolium salicylate (BSL) crystal for NLO applications are reported.

\section{Materials and Methods}

2.1. Synthesis and Crystal Growth. Analar grade Benzimidazole and salicylic acid were taken in 1:1 molar ratio and dissolved completely in methanol. The mixture was stirred well for about 6 hrs. The reaction involved is illustrated in Figure 1. Suspended impurities were removed by using Whatman 41 grade filter paper. The clear filtrate so obtained was kept aside in a dust-free room for the growth of single crystal. The purity of synthesized compound BSL was improved by successive recrystallization process and filtration. Optically good transparent, colourless crystal having dimensions $19 \times 9 \times 4 \mathrm{~mm}^{3}$ with perfect external morphology was harvested within a period of 1 week and the grown crystal is shown in Figure 2.

\section{Characterization Studies}

3.1. Single Crystal X-Ray Diffraction Studies. Single crystal $\mathrm{X}$-ray diffraction analysis of the grown crystal was carried out using ENRAF NONIUS CAD-4 X-ray diffractometer equipped with monochromated $\operatorname{MoK} \alpha$ radiation $(\lambda=$ $0.71073 \AA$ ). It is found that the crystal belongs to monoclinic crystal system with space group $\mathrm{P} 2_{1} / c$. The crystal data and the structure refinement for BSL crystal is given in Table 1. The structure of the BSL crystal has been solved by direct methods and refined by full-matrix least square techniques using SHELXL-97 program to an $R$ value of 0.0481 . The ORTEP diagram of the molecular structure of the grown BSL single crystal is shown in Figure 3. The title salt consists of a $\mathrm{C}_{7} \mathrm{H}_{7} \mathrm{~N}_{2}{ }^{+}$cation and $\mathrm{C}_{7} \mathrm{H}_{5} \mathrm{O}_{3}{ }^{-}$anion in the asymmetric unit. The cation is protonated at $\mathrm{N}$ atom. The dihedral angle between the benzimidazolium and benzene rings is $75.88(5)^{\circ}$. The molecular structure is stabilized by weak O-- -H...O hydrogen bond which generates $\mathrm{S}(6)$ graph-set motif. In the crystal structure, the weak intermolecular N---H...O, C-- -H...O hydrogen bonds link the adjacent anions and cations. The crystal packing is further influenced by weak C-H... $\Pi$ and $\Pi \ldots \Pi\left[\mathrm{Cg} 1 . . . C g 1{ }^{(\mathrm{i})}\right.$ distance $=3.4156(7) \AA$; Cg1...Cg2 $2^{\text {(ii) }}$ distance $=3.8196(8) \AA$; (i) $2-x, 2-y,-z$; (ii) $3-x, 2-y,-z$; $\mathrm{Cg} 1$ and $\mathrm{Cg} 2$ are the centroids of the rings $(\mathrm{N} 1 / \mathrm{C} 8 / \mathrm{C} 13 / \mathrm{N} 2 / \mathrm{C} 14)$ and $(\mathrm{C} 8-\mathrm{C} 13)$, resp.] interactions, forming a three-dimensional network.

3.2. High-Resolution X-Ray Diffractometry (HRXRD) Analysis. The rocking curves of the BSL crystals for the diffraction planes $\left(\begin{array}{lll}0 & 0 & 1\end{array}\right)$ were recorded in symmetrical Bragg geometry using the natural facets by performing $\omega$ scan with doubleaxis geometry [24]. The monochromated X-ray beam incident on the specimen was obtained using a high-resolution four-bounce $\mathrm{Ge}\left(\begin{array}{lll}2 & 2 & 0\end{array}\right)$ monochromator. A scintillation detector was used to record the diffracted beam from the crystal sample without using any analyzer at the receiving stage before the detector to get all the possible information like the individual peaks from structural grain boundaries, scattered intensity from the dislocations, and other defects from the specimen crystal. Figure 4 shows the recorded high resolution X-ray diffraction curve for a typical BSL crystal specimen using $\left(\begin{array}{lll}0 & 0 & 1\end{array}\right)$ diffracting planes in symmetrical Bragg geometry by employing the multicrystal X-ray diffractometer with MoK $\alpha 1$ radiation. The DC contains a single peak and indicates that the specimen is free from structural grain boundaries. The FWHM (full width at half maximum) of the curve is 158 arcsec which is close to the perfect real life crystal. The low values of FWHM and the low angular spread of around 500 arcsec of the DC indicate that the crystalline perfection is reasonably good. Growth conditions as well as 
TABLE 1: Crystal data and structure refinement for BSL crystal.

\begin{tabular}{|c|c|c|}
\hline Empirical formula & $\mathrm{C}_{14} \mathrm{H}_{12} \mathrm{~N}_{2} \mathrm{O}_{3}$ & \\
\hline Formula weight & 256.26 & \\
\hline Temperature & $295(2) \mathrm{K}$ & \\
\hline Wavelength & $0.71073 \AA$ & \\
\hline Crystal system & Monoclinic & \\
\hline \multirow[t]{2}{*}{ Space group } & $\mathrm{P} 2_{1} / c$ & \\
\hline & $a=7.4776(3) \AA$ & $\alpha=90^{\circ}$ \\
\hline \multirow[t]{2}{*}{ Unit cell dimensions } & $b=6.7002(2) \AA$ & $\beta=94.445(2)^{\circ}$. \\
\hline & $c=24.9017(9) \AA$ & $\gamma=90^{\circ}$ \\
\hline Volume & $1243.86(8) \AA^{3}$ & \\
\hline$Z$ & 4 & \\
\hline Density (calculated) & $1.368 \mathrm{Mg} / \mathrm{m}^{3}$ & \\
\hline Absorption coefficient & $0.098 \mathrm{~mm}^{-1}$ & \\
\hline$F(000)$ & 536 & \\
\hline Crystal size & $0.34 \times 0.30 \times 0.25 \mathrm{~mm}^{3}$ & \\
\hline Theta range for data collection & 2.73 to $39.35^{\circ}$ & \\
\hline Index ranges & $-10 \leq h \leq 10,-11 \leq k \leq 9,-35 \leq l \leq 35$ & \\
\hline Reflections collected & 23125 & \\
\hline Independent reflections & $4606[R($ int $)=0.0244]$ & \\
\hline Completeness to theta $=25.00^{\circ}$ & $99.9 \%$ & \\
\hline Absorption correction & Semiempirical from equivalents & \\
\hline Max. and min. transmission & 0.9759 and 0.9674 & \\
\hline Refinement method & Full-matrix least squares on $F^{2}$ & \\
\hline Data/restraints/parameters & $4606 / 1 / 176$ & \\
\hline Goodness-of-fit on $F^{2}$ & 1.031 & \\
\hline Final $R$ indices $[I>2 \operatorname{sigma}(I)]$ & $R 1=0.0481, w R 2=0.1237$ & \\
\hline$R$ indices (all data) & $R 1=0.0822, w R 2=0.1422$ & \\
\hline Extinction coefficient & $0.025(3)$ & \\
\hline Largest diff. peak and hole & 0.348 and $-0.259 \mathrm{e} \AA^{-3}$ & \\
\hline
\end{tabular}

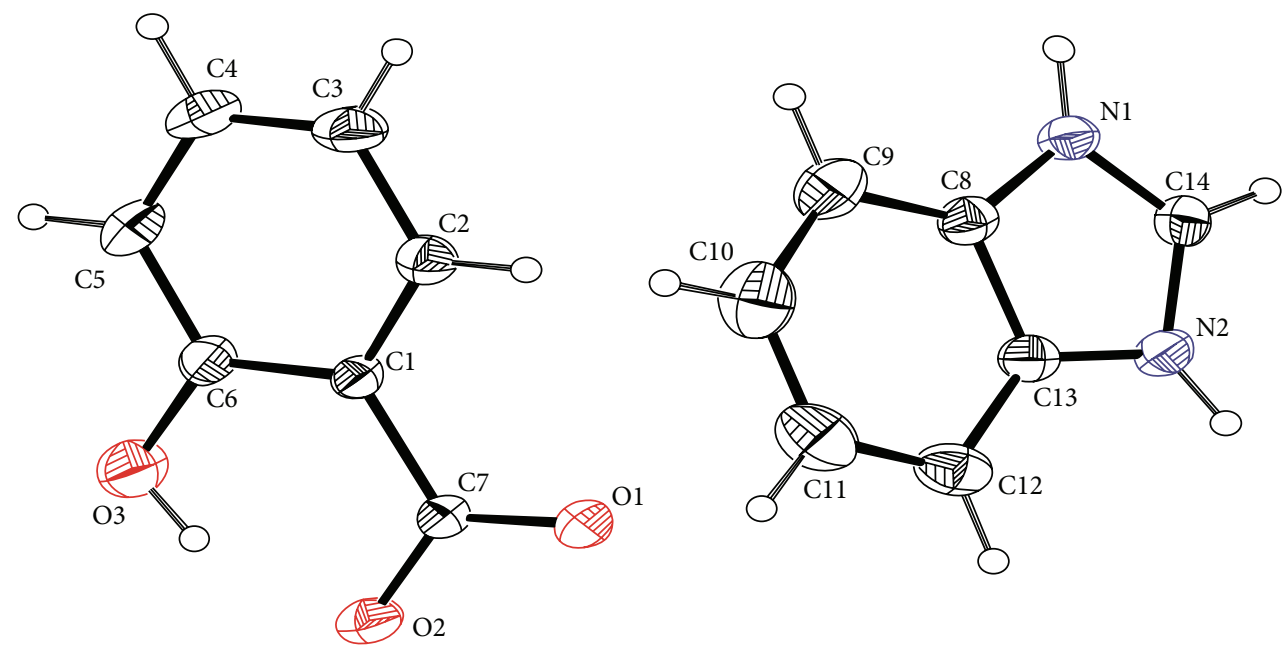

FIGURE 3: ORTEP diagram of BSL crystal. 


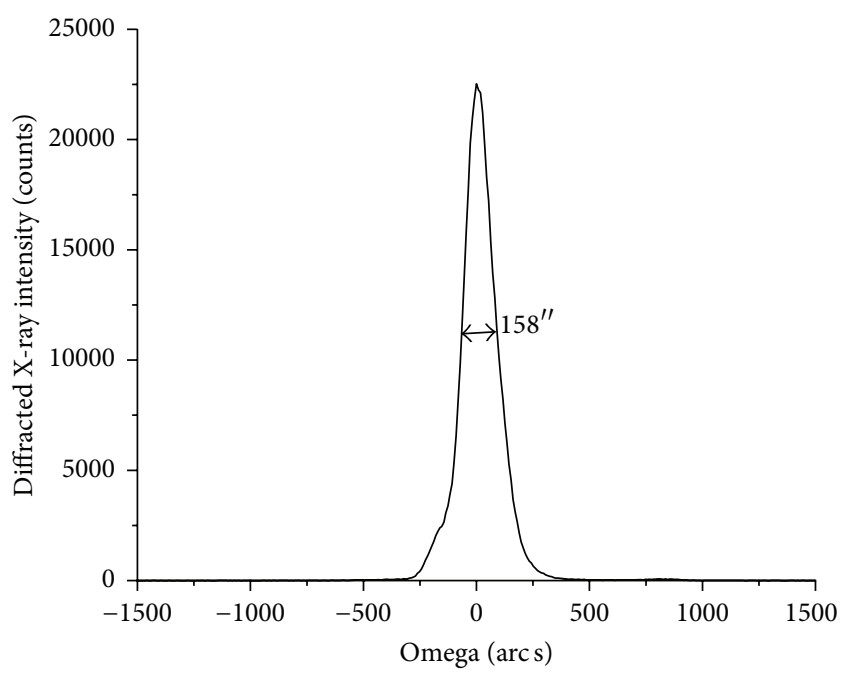

FIGURE 4: HRXRD curve of BSL crystal.

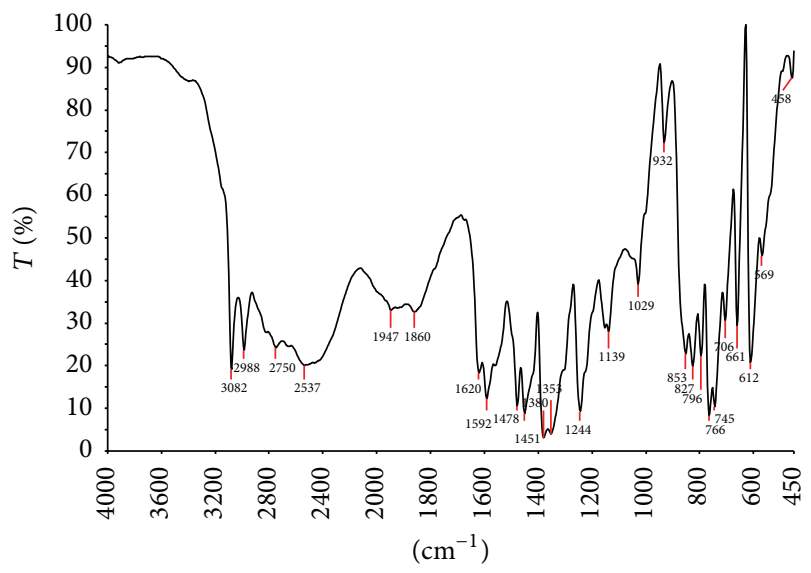

FIgURE 5: FTIR Spectrum of BSL.

thermodynamic considerations also result in point defects in the crystals and are unavoidable up to some extent [25].

3.3. FT-IR Spectrum. The FT-IR spectrum of benzimidazolium salicylate was recorded in the range $4000-400 \mathrm{~cm}^{-1}$ (Figure 5). It is evident from the spectrum that the band at $3339 \mathrm{~cm}^{-1}$ is assigned to the $\mathrm{OH}$ asymmetric stretching vibration. The bands at 3082 and $2988 \mathrm{~cm}^{-1}$ are due to aromatic $\mathrm{C}-\mathrm{H}$ asymmetric and symmetric stretching vibrations of Benzimidazole, respectively. The $\mathrm{C}=\mathrm{O}$ vibration of $\mathrm{COO}^{-}$ in salicylate gives its peak at $1620 \mathrm{~cm}^{-1}$. In free salicylic acid $\mathrm{C}=\mathrm{O}$ vibration occurs at $1750 \mathrm{~cm}^{-1}$. The shift towards low value, therefore, illustrates the transfer of carboxylic proton from carboxylic acid to Benzimidazole. The bands at 1592, 1478,1451 , and $1380 \mathrm{~cm}^{-1}$ are assigned to the aromatic $\mathrm{C}=\mathrm{C}$ stretching vibrations of Benzimidazole ring which once again verifies the presence of Benzimidazole in the crystal [26]. The band observed at $1139 \mathrm{~cm}^{-1}$ is assigned to $\mathrm{C}-\mathrm{H}$ inplane bending vibration of benzimidazolium ring [27]. The band at $1353 \mathrm{~cm}^{-1}$ is due to $\mathrm{C}-\mathrm{H}$ bending. A band at $1244 \mathrm{~cm}^{-1}$ is
TABLE 2: The wavenumber and the assignment of vibration of BSL.

\begin{tabular}{ll}
\hline Wavenumber $\left(\mathrm{cm}^{-1}\right)$ & Assignment of vibration \\
\hline 3339 & O-H asymmetric stretching vibration \\
3082,2988 & Aromatic C-H stretching vibration \\
1620 & C=O vibration of Salicylate \\
$1592,1478,1451$, and 1380 & Aromatic C=C stretching vibration \\
1244 & C-O stretching vibration \\
1139 & C-H inplane bending vibration \\
1029,932 & C-N stretching vibration \\
766 & C-H out of plane bending \\
\hline
\end{tabular}

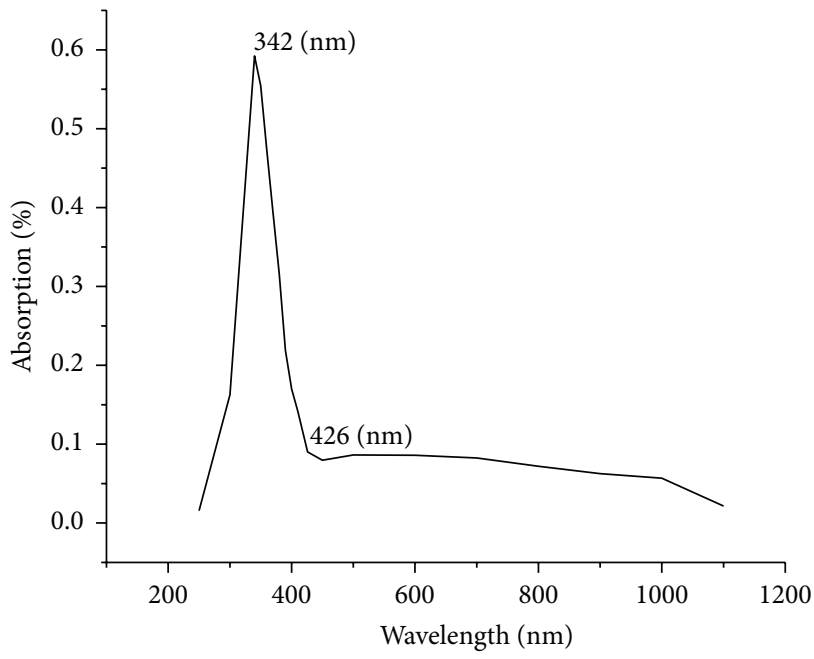

FIGURE 6: Optical absorption spectrum of BSL crystal.

assigned to the $\mathrm{C}-\mathrm{O}$ stretching vibration. The bands at 1029 and $932 \mathrm{~cm}^{-1}$ are assigned to $\mathrm{C}-\mathrm{N}$ stretching vibration. The band at $766 \mathrm{~cm}^{-1}$ is due to the $\mathrm{C}-\mathrm{H}$ out of plane bending of aromatic hydrogen atom. The respective assignments are given in Table 2.

3.4. UV-Vis Absorption Spectral Analysis. The UV-Vis spectrum relinquishes valuable information about the atomic structure of the molecules because the absorption of UV and visible light involves the promotion of $\sigma$ and $\pi$ orbital electrons from the ground state to higher energy state. For device fabrication, this is one of the desirable properties of the crystals. The electronic absorption spectrum of BSL crystal was recorded using Shimadzu 1601 UV-Vis spectrophotometer in the range $200-1100 \mathrm{~nm}$ and is shown in Figure 6. The optical absorption spectrum indicates that the crystal has lower cut-off wavelength of about $342 \mathrm{~nm}$. From the absorption spectrum, it can be observed that there is less absorbance in the entire visible and near-infrared region. The wide transparency and lower cut-off is one of the requirements for having efficient NLO character. The absorption due to electronic transitions above $300 \mathrm{~nm}$ is the key requirement for frequency doubling using diode and solid state lasers [28]. The absorption peak at $342 \mathrm{~nm}$ is assigned to $\pi$ to $\pi^{*}$ transition of the compound which is 


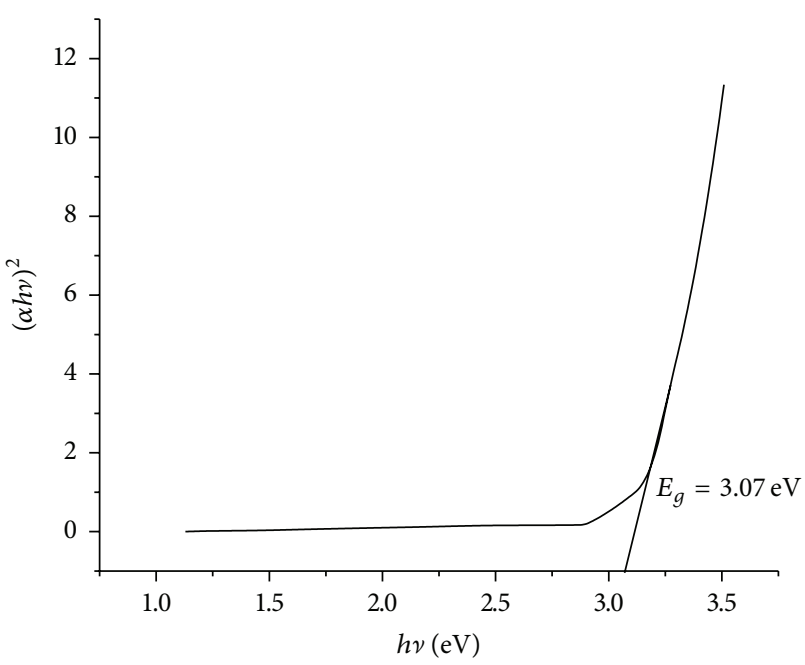

FIGURE 7: Optical band gap of BSL crystal.

attributed to the charge transfer of the compound. Absence of absorption between $400 \mathrm{~nm}$ and $800 \mathrm{~nm}$ is the key requirement for materials possessing SHG properties. Thus BSL crystal can be used as a potential candidate for the SHG device application in the visible region [29]. The UV cut-off wavelength of BSL is comparable with other Benzimidazole derivatives such as benzimidazolium per chlorate $(360 \mathrm{~nm})$ and pure Benzimidazole $(300 \mathrm{~nm})$ and salicylic acid salts like Brucinium 5 sulfosalicylate $(312 \mathrm{~nm})$, Urea salicylic acid $(347 \mathrm{~nm})$, and so forth [18-21, 30].

3.5. Determination of Optical Band Gap. The optical absorption coefficient $(\alpha)$ was calculated from the transmittance using, $\alpha=(1 / d) \log (1 / T)$ where $T$ is the transmittance and $d$ is the thickness of the crystal. The plot of variation of $(\alpha h \nu)^{2}$ versus $h \nu$ is shown in Figure 7. The band gap energy $E_{g}$ is evaluated by the extrapolation of the linear part. The band gap was found to be $3.07 \mathrm{eV}$. The transmittance increases while the band gap becomes wider. The wide band gap energy confirms the good optical transparency and dielectric behaviour of the crystal [31]. It also ensures the crystal suitability for optoelectronic device application, optical harmonic generation, and so forth [32].

3.6. Dielectric Studies. The capacitance $(C)$ and dielectric loss $(\tan \delta)$ were measured using the conventional parallel plate capacitor connected with HIOKI-LCR Hi-Tester 3532 at temperatures $308 \mathrm{~K}, 318 \mathrm{~K}$, and $328 \mathrm{~K}$ with frequency range of $50 \mathrm{~Hz}$ to $6 \mathrm{MHz}$. The dielectric studies of BSL crystal was performed with a crystal of dimension $19 \times 9 \times 4 \mathrm{~mm}^{3}$ which was coated with good quality graphite to obtain a good conductive surface layer. The variation of dielectric constant and dielectric loss as a function of $\log f$ at different temperatures are shown in Figures 8 and 9.

It is observed from Figure 8 that the dielectric constant decreases with increasing frequency and finally it becomes almost a constant at higher frequencies for all temperatures. The dielectric constant has a high value of 505 at $100 \mathrm{~Hz}$

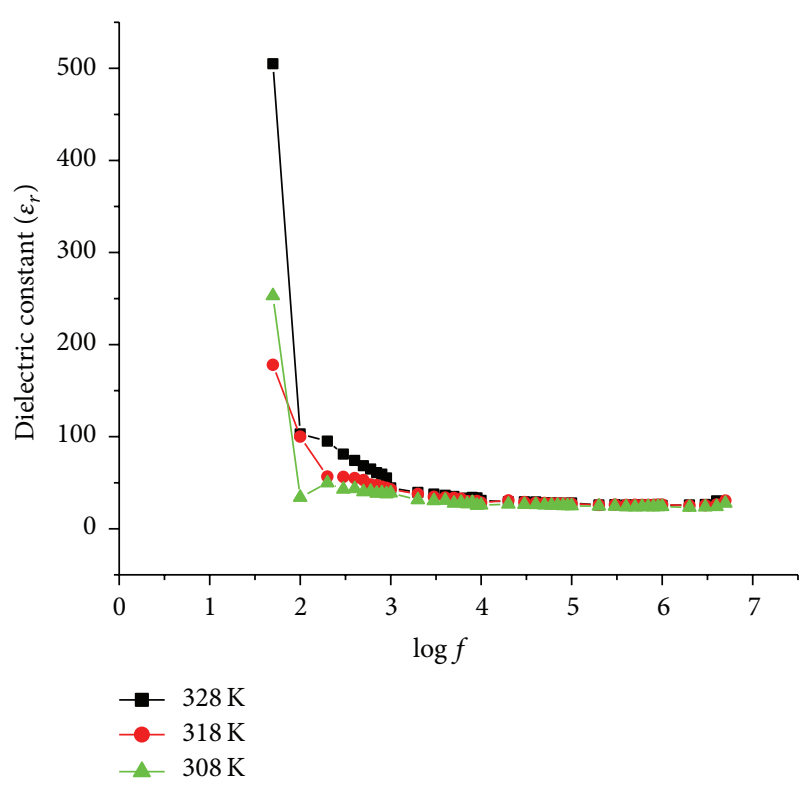

Figure 8: Plot of dielectric constant and $\log f$.

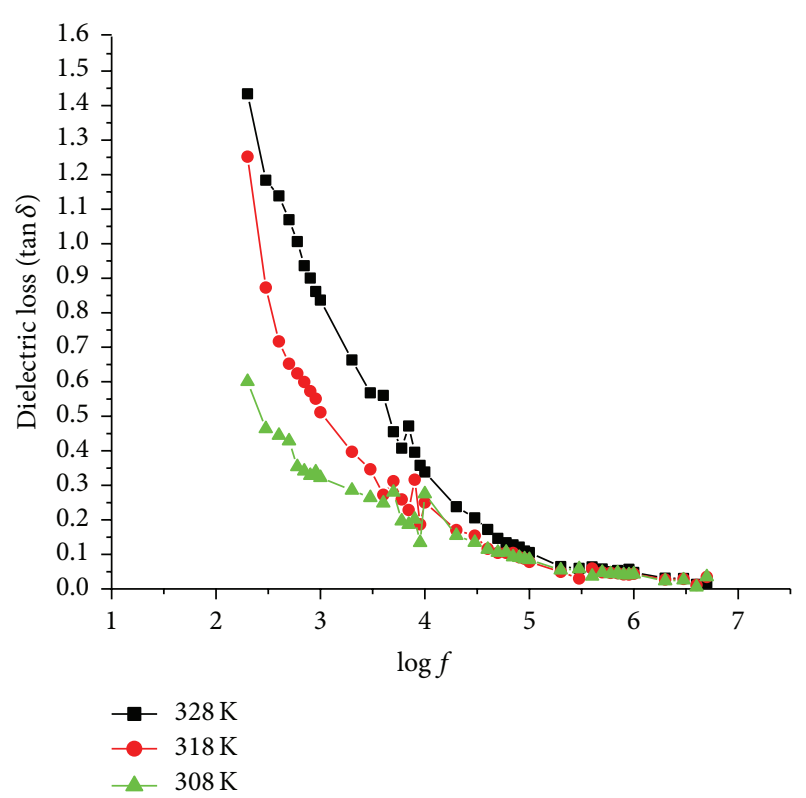

FIgURE 9: Plot of dielectric loss and $\log f$.

and decreases to 23 at $6 \mathrm{MHz}$. The higher value of dielectric constant at lower frequency region may be due to the presence of all the four types of polarization, namely, space charge, orientation, and ionic and electronic polarizations. The lower value of dielectric constant at higher frequency was due to the loss of significance of these polarizations gradually. Space charge polarization is generally active at lower frequencies and high temperatures which signifies the perfection of the crystal. The variation of dielectric loss at different frequencies and temperatures (Figure 9) shows the same trend as dielectric constant. The crystal undergoes piezoelectric resonance at $10 \mathrm{KHz}$ where the frequency of the electric field matches 


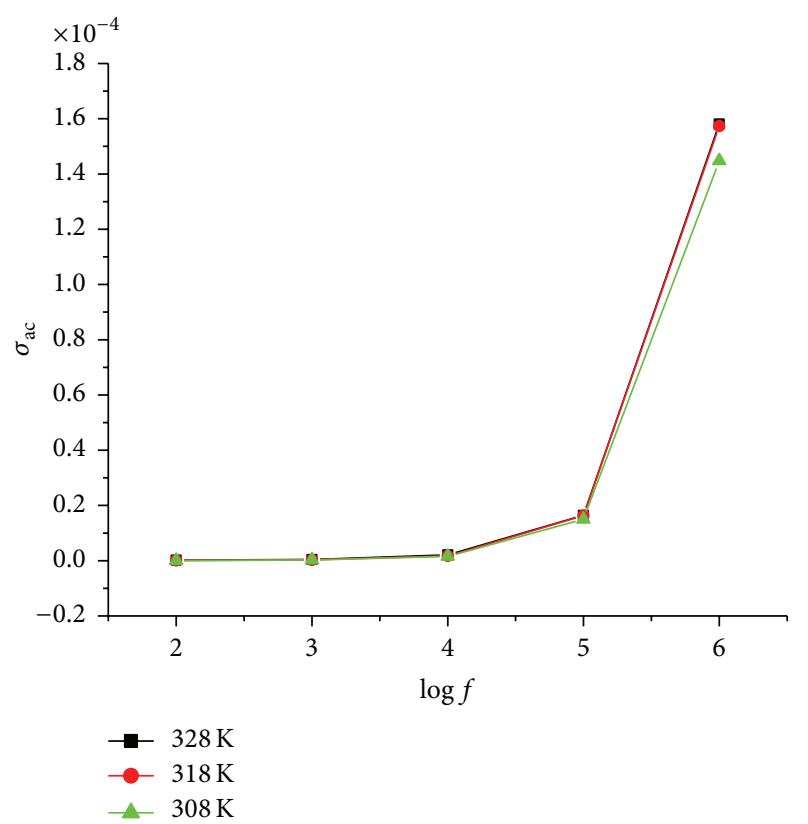

Figure 10: Plot of ac conductivity and $\log f$ for varying temperatures.

the frequency of the vibration of the crystal [33]. Also the temperature dependence of dielectric constant and dielectric loss can be explained as being due to temperature dependence of protonic movement and ionic polarizability [34]. The considerable low value of dielectric constant at higher frequencies indicates that the crystal can be used in photonic, electrooptic, and NLO devices. Moreover the low dielectric losses at higher frequencies indicate that the grown BSL crystal is of good quality with lesser defects and is an important parameter for nonlinear optical material in their applications [35].

The alternating current conductivity $\left(\sigma_{\mathrm{ac}}\right)$ is calculated using the relation [36]

$$
\sigma_{\mathrm{ac}}=2 \pi f \epsilon_{0} \epsilon_{r} \tan \delta,
$$

where $f$ is the frequency of the applied ac field $(\mathrm{Hz}), \epsilon_{0}$ is the permittivity of free space, and $\epsilon_{r}$ and $\tan \delta$ are the measured values of dielectric constant and dielectric loss of the material. The ac conductivity plot with temperature for varying frequency is shown in Figure 10. This plot shows that the ac conductivity increases with frequency and temperature which indicates the normal dielectric behaviour of BSL crystal.

3.7. Vickers Microhardness Analysis. The mechanical properties of crystals are determined by mechanical testing which enables us to study the mechanical characteristics of crystals. The Vickers microhardness study was made on the as grown face of BSL for the static indentation test in air at room temperature using Leitz Wetzlar hardness tester fitted with Vickers diamond pyramidal indentor. The Vickers hardness number was calculated using the expression

$$
H_{v}=1.854\left(\frac{P}{d^{2}}\right)
$$

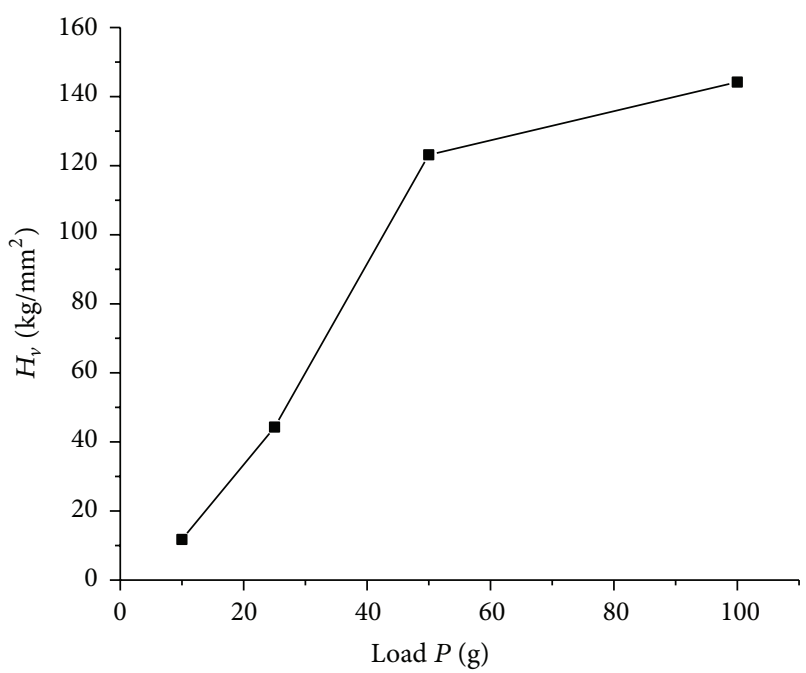

Figure 11: Variation of Vickers hardness number $H_{v}$ with load $P$.

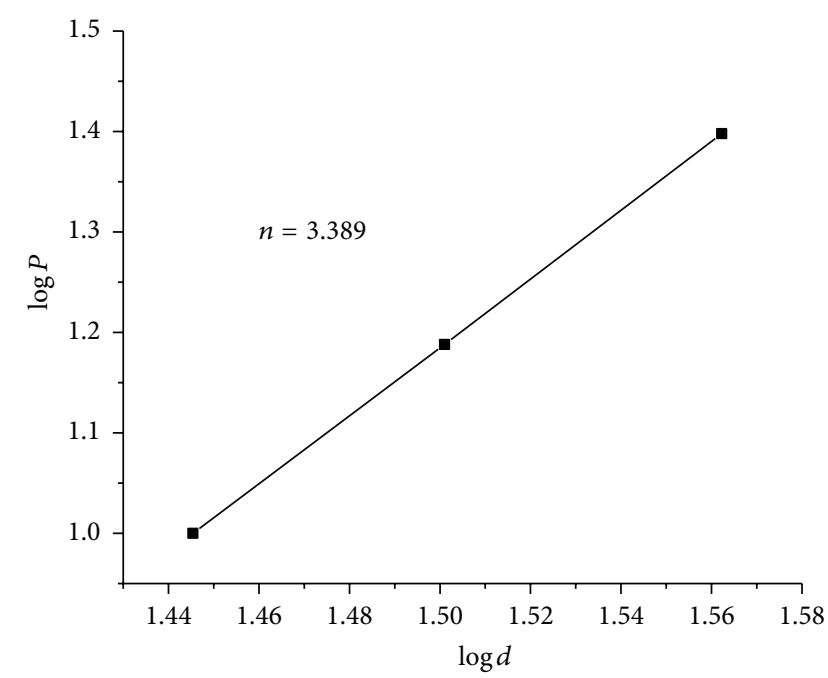

Figure 12: Plot between $\log P$ and $\log d$.

where $H_{v}$ is the Vickers hardness number for a given load, $P$, in gram and $d$ is the average diagonal length of the indentation in mm. For loads ranging from 25 to $100 \mathrm{gm}$, the microhardness values of BSL were found to be increasing with load. The plot of $H_{v}$ versus load $P$ is shown in Figure 11. The Mayer index number was calculated from Mayer's law which relates the load and indentation diagonal length. Consider

$$
\begin{aligned}
P & =k d^{n}, \\
\log P & =\log k+n \log d,
\end{aligned}
$$

where $k$ is the material constant and $n$ is work-hardening coefficient. The plot between $\log P$ and $\log d$ is shown in Figure 12. According to Onitsch $n$ should lie between 1 and 1.6 for harder materials and above 1.6 for softer materials [37]. The work-hardening coefficient $(n)$ was calculated to be 3.389 from the slope of $\log P$ versus $\log d$. Thus the BSL crystal belongs to soft material category. 
TABLE 3: SHG efficiency of various centrosymmetric materials.

\begin{tabular}{lcc}
\hline Sample & Space group & SHG with KDP \\
\hline $\begin{array}{l}\text { Diimidazolium dipicrate } \\
\text { monohydrate [42] }\end{array}$ & $\mathrm{P} 2_{1} / m$ & 0.2 \\
\hline $\begin{array}{l}\text { (p-Nitrophenol, } \\
\text { hexamethylenetetramine, } \\
\text { Phosphoric acid, and water) } \\
\text { supramolecular crystal [43] }\end{array}$ & $\mathrm{P} 2_{1} / c$ & 3.1 \\
\hline R,S-serine [7] & $\mathrm{P} 2_{1} / a$ & 0.02 \\
\hline $\begin{array}{l}\text { Glycine picrate [44] } \\
\begin{array}{l}\text { Guanidinium } \\
\text { trifluoroacetate [45] }\end{array}\end{array}$ & $\mathrm{Pbcn}$ & 2.34 \\
\hline $\begin{array}{l}\text { Benzimidazolium salicylate } \\
\text { [present work] }\end{array}$ & $\mathrm{P} 2_{1} / c$ & 0.87 \\
\hline
\end{tabular}

3.8. SHG Efficiency Analysis. The SHG conversion efficiency of benzimidazolium salicylate was determined by Kurtz's Perry technique. The crystal was ground into a very fine powder and tightly packed in a microcapillary tube. Then it was mounted in the path of Nd:YAG laser beam of energy $1.9 \mathrm{~mJ} / \mathrm{s}$. The output of $44 \mathrm{mV}$ was obtained for the grown sample. When KDP crystal of the same size was used as a reference material an output of $64 \mathrm{mV}$ was obtained. Hence the grown crystal has an efficiency of about 0.7 times greater than that of KDP.

The criteria for SHG may also be satisfied by centrosymmetric molecule if they aggregate in a noncentrosymmetric manner and there is a contribution to the bulk susceptibility from intermolecular charge transfer [5]. Most molecules like paranitro aniline have very large SHG at the molecular scale due to the charge transfer from the donor to the acceptor crystallize in a centrosymmetric lattice due to predominating antiparallel $\pi$-stacking between the aromatic rings as a consequence of dipolar interactions [38, 39]. Even though the material belongs to centrosymmetric it exhibits SHG activity due to intermolecular hydrogen bonding and charge transfer interactions between the donor and acceptor systems. The SHG in BSL crystal is due to weak interaction between the dipoles, which is easy for the ground state to turn into the excited state as a charge separated form and generate the stable asymmetrical distribution of $\pi$ electron cloud density thus exhibiting a minimum SHG effect [40, 41]. The SHG efficiency of BSL crystal is compared with other reported SHG efficiencies of centrosymmetric materials and is tabulated in Table 3.

\section{Conclusion}

The organic molecular complex salt BSL was synthesized and grown as single crystal by slow evaporation solution growth technique at room temperature with methanol as the solvent. The single crystal XRD confirms that the BSL crystal belongs to monoclinic system with the centrosymmetric space group $\mathrm{P} 2_{1} / c$. The functional groups present in the grown crystal have been confirmed by FT-IR spectral analysis. The UV-Vis spectral analysis reveals high transparency of BSL crystal in the entire visible region. The optical band gap energy $\left(E_{g}\right)$ of the BSL crystal is $3.07 \mathrm{eV}$. The mechanical stability of BSL was determined using Vickers microhardness analysis. The high resolution X-ray diffraction (HRXRD) of the crystal shows that the perfection of the crystal is quite good. Dielectric measurements were carried out to analyse the dielectric constant and dielectric loss at different frequencies and at different temperature. The powder SHG efficiency of BSL is 0.7 times that of KDP. The SHG effect from the centrosymmetric crystal is a remarkable experimental observation and it is concluded that BSL is a potential material for photonic device fabrication.

\section{Conflict of Interests}

The authors declare that there is no conflict of interests regarding the publication of this paper.

\section{Acknowledgment}

The authors thank Professor P. K. Das, Department of Inorganic and Physical Chemistry, IISC, Bangalore, for the measurement of powder SHG efficiency.

\section{References}

[1] D. S. Chemla and J. Zyss, Nonlinear Optical Properties of Organic Molecule and Crystals, Academic Press, New York, NY, USA, 1987.

[2] P. N. Prasad and D. J. Williams, Introduction to Nonlinear Optical Effects in Molecules and Polymers, Wiley, New York, NY, USA, 1991.

[3] J. Badan, R. Hierle, A. Perigand, and J. Zyss, Nonlinear Optical Properties of Organic Molecules and Polymeric Materials, vol. 233 of edited by: Williams, American Chemical Society, Washington, DC, USA, 1993.

[4] C. Bosshard, M. Bösch, I. Liakatas, M. Jäger, and P. Günter, "Second-order nonlinear optical organic materials: recent developments," in Nonlinear Optical Effects and Materials, vol. 72 of Springer Series in Optical Sciences, pp. 163-299, Springer, Berlin, Germany, 2000.

[5] A. Chandramohan, R. Bharathikannan, J. Chandrasekaran, P. Maadeswaran, R. Renganathan, and V. Kandavelu, "Synthesis, crystal growth and characterization of a new organic NLO material: caffeinium picrate (CAFP) - a charge transfer molecular complex salt," Journal of Crystal Growth, vol. 310, no. 24, pp. 5409-5415, 2008.

[6] P. Pandi, G. Peramaiyan, S. Sudhahar et al., "Studies on synthesis, growth, structural, thermal, linear and nonlinear optical properties of organic picolinium maleate single crystals," Spectrochimica Acta-Part A: Molecular and Biomolecular Spectroscopy, vol. 98, pp. 7-13, 2012.

[7] K. E. Rieckhoff and W. L. Peticolas, "Optical second-harmonic generation in crystalline amino acids," Science, vol. 147, no. 3658, pp. 610-611, 1965.

[8] W. Guo, F. Guo, C. Wei et al., "SHG from centrosymmetric supermolecular crystal," Science in China Series B: Chemistry, vol. 45, no. 3, pp. 267-274, 2002. 
[9] A. Criado, M. J. Diánez, S. Pérez-Garrido, I. M. L. Fernandes, M. Belsley, and E. De Matos Gomes, "1,1,3,3-tetramethylguanidinium dihydrogenorthophosphate," Acta Crystallographica, vol. 56, no. 7, pp. 888-889, 2000.

[10] J. Zaccaro, J. P. Salvastrini, A. Ibanez, P. Ney, and M. D. J. Fontana, "Electric-field frequency dependence of Pockels coefficients in 2-amino-5-nitropyridium dihydrogen phosphate organic-inorganic crystals," Journal of the Optical Society of America B, vol. 17, no. 3, pp. 427-432, 2000.

[11] A. Chandramohan, R. Bharathikannan, M. A. Kandhaswamy, J. Chandrasekaran, R. Renganathan, and V. Kandavelu, "Synthesis, spectral, thermal and NLO properties of N,N-dimethyl anilinium picrate," Crystal Research and Technology, vol. 43, no. 2, pp. 173-178, 2008.

[12] A. Chandramohan, D. Gayathri, D. Velmurugan, K. Ravikumar, and M. A. Kandhaswamy, "1,3,7-Trimethylxanthenium 2,4,6trinitrophenolate," Acta Crystallographica Section E, vol. 63, no. 5, pp. 2495-2496, 2007.

[13] S. Ueda, T. Fukunaga, and H. Ishida, "Benzimidazolium hydrogen phenylmalonate," Acta Crystallographica Section E, vol. 61, pp. o1845-o1847, 2005.

[14] T.-T. Pan, J.-G. Liu, and D.-J. Xu, "Benzimidazolium hydrogen nitroterephthalate," Acta Crystallographica Section E: Structure Reports Online, vol. 61, no. 12, pp. o3996-o3997, 2005.

[15] M. Obulichetty and D. Saravanabharathi, "Influence of molecular structure on the photoluminescence of 2-methyl benzimidazolium picrate: a new fluorescent material," Spectrochimica Acta-Part A: Molecular and Biomolecular Spectroscopy, vol. 118, pp. 861-866, 2014.

[16] R. Walia, M. Hedaitullah, F. S. Naar, K. Iqbal, and H. S. Lamba, "Benzimidazole derivatives-an overview," International Journal of Research in Pharmacy and Chemistry, vol. 1, no. 3, pp. 565-573, 2011.

[17] R. S. Mulliken, "Structures of complexes formed by halogen molecules with aromatic and with oxygenated solvents," Journal of the American Chemical Society, vol. 72, no. 1, pp. 600-608, 1950.

[18] M. Rajalakshmi, R. Indirajith, P. Ramasamy, and R. Gopalakrishnan, "Synthesis, growth and characterization of $1 \mathrm{H}$-benzimidazolium hydrogen L-tartrate dihydrate single crystals," Molecular Crystals and Liquid Crystals, vol. 548, no. 1, pp. 126-141, 2011.

[19] R. R. Babu, M. Sukumar, V. Vasudevan, M. Shakir, K. Ramamurthi, and G. Bhagavannarayana, "Growth and properties of benzil doped benzimidazole (BMZ) single crystals," Materials Research Bulletin, vol. 45, no. 9, pp. 1197-1198, 2010.

[20] L. Mariappan, A. Kandasamy, M. Rathnakumari, and P. Sureshkumar, "Synthesis, growth and properties of a novel organic nonlinear optical material: benzimidazolium perchlorate," Optik, vol. 124, no. 22, pp. 5707-5710, 2013.

[21] C. Andal and P. Murugakoothan, "Growth of urea salicylic acid (USA) crystal," International Journal of ChemTech Research, vol. 6, no. 3, pp. 1541-1543, 2014.

[22] M. Dhavamurthy, G. Peramaiyan, K. S. S. Babu, and R. Mohan, "Crystal growth, morphology, thermal and spectral studies of an organosulfur nonlinear optical bis(guanidinium) 5-sulfosalicylate (BG5SS) single crystals," Applied Physics A, vol. 119, no. 1, pp. 155-161, 2015.

[23] K. Gayathri, P. Krishnan, P. R. Rajkumar, and G. Anbalagan, "Growth, optical, thermal and mechanical characterization of an organic crystal: brucinium 5-sulfosalicylate trihydrate," Bulletin of Materials Science, vol. 37, no. 7, pp. 1589-1595, 2014.
[24] G. Bhagavannarayana and S. K. Kushwaha, "Enhancement of SHG efficiency by urea doping in ZTS single crystals and its correlation with crystalline perfection as revealed by Kurtz powder and high-resolution X-ray diffraction methods," Journal of Applied Crystallography, vol. 43, no. 1, pp. 154-162, 2010.

[25] G. Bhagavannarayana, P. Rajesh, and P. Ramasamy, "Interesting growth features in potassium dihydrogen phosphate: unravelling the origin and dynamics of point defects in single crystals," Journal of Applied Crystallography, vol. 43, pp. 1372-1376, 2010.

[26] N. Vijayan, R. Ramesh Babu, R. Gopalakrishnan, P. Ramasamy, and W. T. A. Harrison, "Growth and characterization of benzimidazole single crystals: a nonlinear optical material," Journal of Crystal Growth, vol. 262, no. 1-4, pp. 490-498, 2004.

[27] R. M. Silverstein and F. X. Webster, Spectrometric Identification of Organic Compounds, John Wiley \& Sons, Québec, Canada, 6th edition, 1998.

[28] V. G. Dmitriev, G. G. Gurzadyan, and D. N. Nikoyosyan, Handbook of Nonlinear Optical Crystals, Springer, Berlin, Germany, 1999.

[29] K. Kirubavathi, K. Selvaraju, N. Vijayan, and S. Kumararaman, "Synthesis growth and characterization of L-Valinium Picrate a new nonlinear optical crystal," Spectrochimica Acta Part A: Molecular and Biomolecular Spectroscopy, vol. 71, no. 1, pp. 288291, 2008.

[30] S. Rajasekar, M. Vimalan, N. Vijayan, and P. S. Joseph, "Growth and dielectric studies of benzimidazole: a novel organic NLO material," Archives of Applied Science Research, vol. 4, no. 2, pp. 1022-1027, 2012.

[31] D. D. O. Eya, A. J. Ekpunobi, and C. E. Okeke, "Influence of thermal annealing on the optical properties of tin oxide thin films prepared by chemical bath deposition technique," Academic Open Internet Journal, vol. 17, 2006.

[32] P. Rajesh and P. Ramasamy, "Growth of dl-malic acid-doped ammonium dihydrogen phosphate crystal and its characterization," Journal of Crystal Growth, vol. 311, no. 13, pp. 3491-3497, 2009.

[33] R. R. Babu, M. Sukumar, V. Vasudevan, M. Shakir, K. Ramamurthi, and G. Bhagavannarayana, "Growth and properties of benzil doped benzimidazole (BMZ) single crystals," Materials Research Bulletin, vol. 45, no. 9, pp. 1194-1198, 2010.

[34] V. A. Hiremath and A. Venkataraman, "Dielectric, electrical and infrared studies of $\gamma-\mathrm{Fe}_{2} \mathrm{O}_{3}$ prepared by combustion method," Bulletin of Materials Science, vol. 26, no. 4, pp. 391-396, 2003.

[35] U. Charoen-In, P. Ramasamy, and P. Manyum, "Comparative study on l-alaninium maleate single crystal grown by Sankaranarayanan-Ramasamy (SR) method and conventional slow evaporation solution technique," Journal of Crystal Growth, vol. 312, no. 16-17, pp. 2369-2375, 2010.

[36] B. Lal, K. K. Bamzai, P. N. Kotru, and B. M. Wanklyn, "Microhardness, fracture mechanism and dielectric behaviour of fluxgrown $\mathrm{GdFeO}_{3}$ single crystals," Materials Chemistry and Physics, vol. 85, no. 2-3, pp. 353-365, 2004.

[37] E. M. Onitsch, "Micro-hardness testing," Mikroscopia, vol. 2, pp. 131-151, 1947.

[38] S. C. Abraham and J. M. Robertson, "The crystal structure of p-nitroaniline, $\mathrm{NO}_{2} \cdot \mathrm{C}_{6} \mathrm{H}_{4} \cdot \mathrm{NH}_{2}$," Acta Crystallographica, vol. 1, pp. 252-259, 1948.

[39] J. Donhue and K. N. Trueblood, "The crystal structure of pnitroaniline," Acta Crystallographica, vol. 9, p. 960, 1956.

[40] G. J. Ashwell, G. Jefferies, D. G. Hamilton et al., "Strong secondharmonic generation from centrosymmetric dyes," Nature, vol. 375, no. 6530, pp. 385-388, 1995. 
[41] W. Nie, "Optical nonlinearity: phenomena, applications, and materials," Advanced Materials, vol. 5, no. 7-8, pp. 520-545, 1993.

[42] K. Mohana Priyadharshini and A. Chandramohan, "Synthesis, growth, crystal structure and characterization of an organic salt single crystal: diimidazolium dipicrate monohydrate," The Experiment, vol. 25, no. 4, pp. 1759-1774, 2014.

[43] W. Guo, F. Guo, C. Wei et al., "SHG from centrosymmetric supermolecular crystal," Science in China Series B: Chemistry, vol. 45, no. 3, p. 276, 2002.

[44] M. Shakir, S. K. Kushwaha, K. K. Maurya, M. Arora, and G. Bhagavannarayana, "Growth and characterization of glycine picrate-remarkable second-harmonic generation in centrosymmetric crystal," Journal of Crystal Growth, vol. 311, no. 15, pp. 3871-3875, 2009.

[45] M. Loganayaki, V. S. Shankar, P. Ramesh, M. Ponnuswamy, and P. Murugakoothan, "Growth and characterization of guanidinium trifluoroacetate-second harmonic generation from a centrosymmetric crystal," Journal of Minerals \& Materials Characterization \& Engineering, vol. 10, no. 9, pp. 843-853, 2011. 

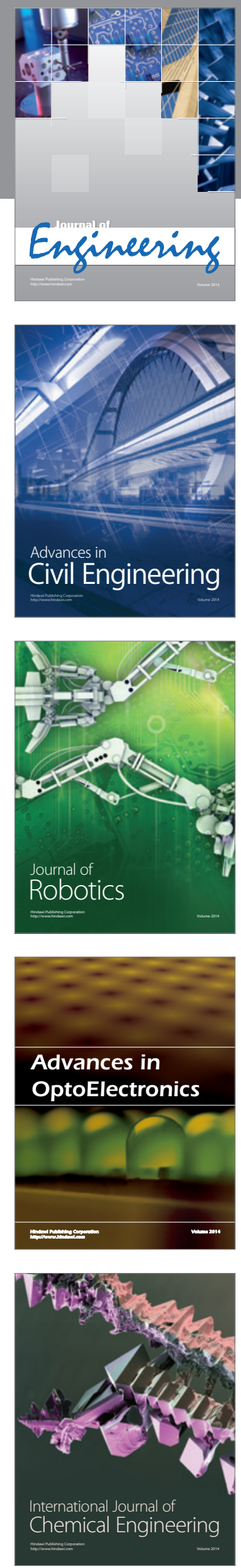

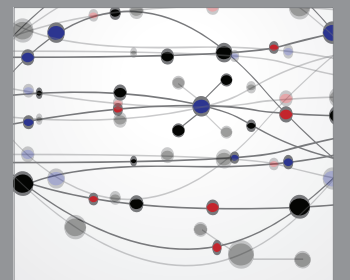

The Scientific World Journal
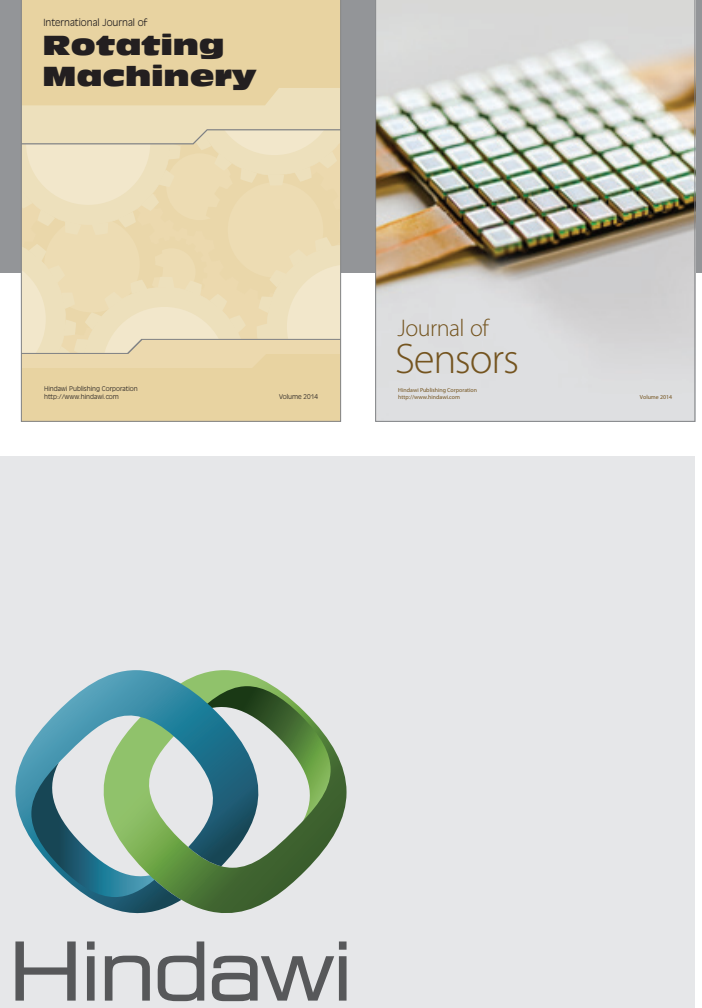

Submit your manuscripts at http://www.hindawi.com
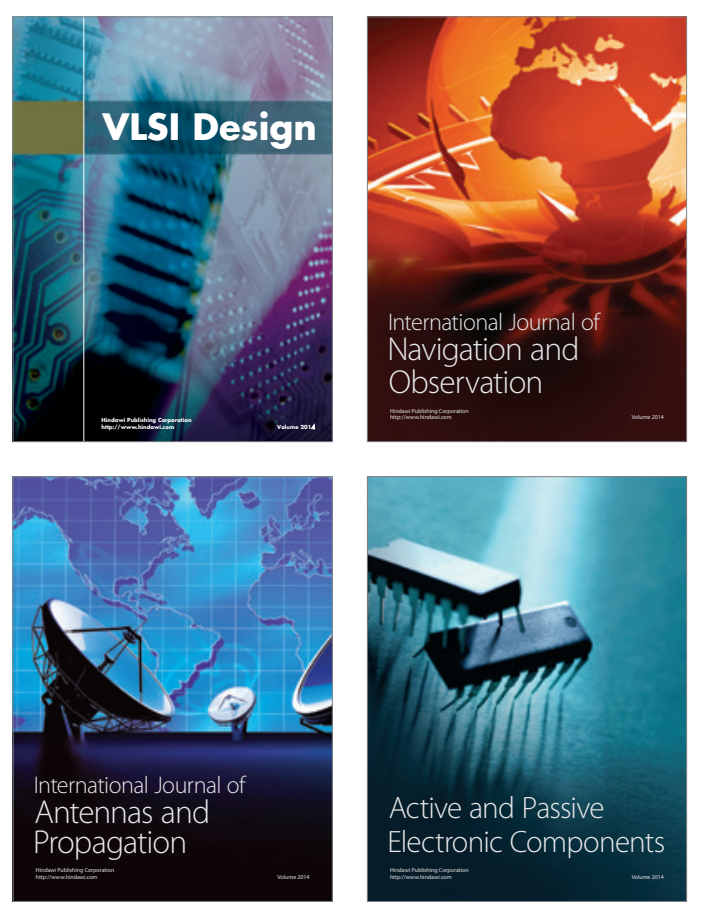
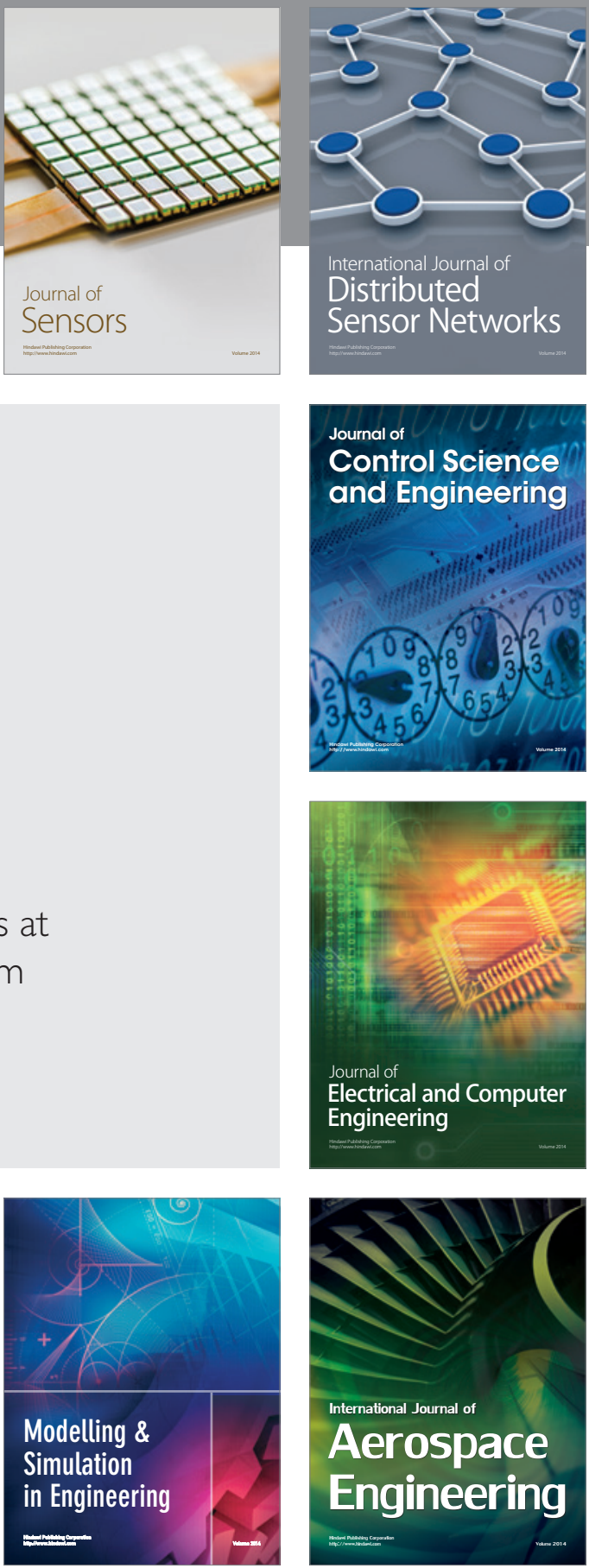

Journal of

Control Science

and Engineering
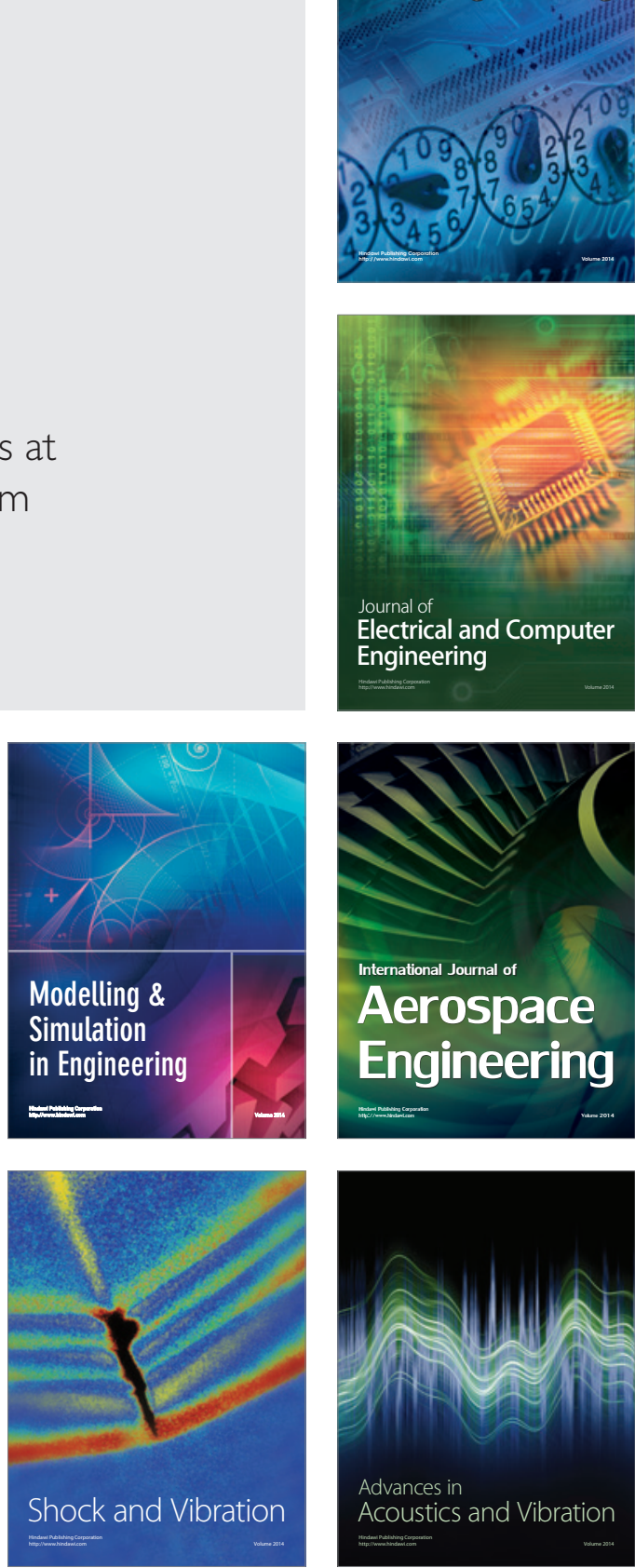